\title{
Developing of Thesaurus Software to Increase the Writing Quality of the Thesis of the Students at the German Language Department
}

\author{
Hafniati $^{1}$, Risnovita Sari ${ }^{2}$, Suci Pujiastuti ${ }^{3}$ \\ 1,2,3 Universitas Negeri Medan, Indonesia \\ Email: afni73@yahoo.com
}

Abstract: The use of academic vocabulary is very important to increase the writing skills and quality of the academic writing of the students. Therefore, Thesaurus software needs to be developed that contains about the academic vocabulary that help the student's writing and increase the quality of their academic writing, and to reduce the plagiarism. The purposes of the research are; (1) to develop of German language vocabulary with a Thesaurus software that increase the quality of academic writing in German (2) to see the effectiveness of German language vocabulary with a Thesaurus software in increasing the quality of academic writing. The special purpose of the research is increasing the quality of student's academic writing from German Language Department at the Universitas Negeri Medan with the use of Thesaurus software for German language vocabulary. The method used is the ADDIE Model with five phases: Analysis, Design, Development, Implementation and Evaluation. The data is taken from the academic writing of the students of German Language Department and the books that used in the Wissenschaftliches Schreiben's (Academic Writing) course and then developed into the German Language academic vocabulary Thesaurus software.

Keywords: Thesaurus; academic vocabulary; wissenschaftliches Schreiben.

\section{Introduction}

A person is mentioned to be able to use good and correct language when they can actively use the language in speaking and writing. For students writing skills are extremely important, because at the end of their studies students should be able to write an academic paper and they moreover should have a good competence especially in thesis writing (Kurniadi, 2017: 1). Competence is defined as knowledge, skills and fundamental values that are reflected in the habits of thinking and acting (Ramlan; Farizawati; Hasrul, 2020: 98).

Since 2008, students of the German language education program at the Universitas Negeri Medan (Unimed) have been required to prepare their thesis in German. For some German students, it is problematic and takes a relatively long time to complete the thesis writing. This is due to difficulties in writing, vocabulary and grammar. In addition to the difficulties that frequently found in the thesis writing of scientific is the equivalent of the words that are not suitable and contain various meanings and expressions (Redemittel) that are less academic or not varied. One of the alternatives used to solve the problem is to use a developed Thesaurus software. Thesaurus has many potential benefits, among them being to write with a more varied vocabulary, knowing the word synonyms or interconnective words. But it is also about academic words commonly used for thesis writing, which need to be known or expressions and academic phrases in the writing of quotations or to facilitate students to paraphrasing quotations in thesis writing (Karmasin, 2011: 10). 
Thesaurus as a learning medium is still rare, especially Thesaurus for writing German academic papers. Thesaurus nevertheless does not exist yet in the Indonesian version of Microsoft Word or other software. In Germany, the software of Thesaurus is exclusively available in the German language for example in Microsoft Word that can be installed on any computer or laptop. Unfortunately, the price of German Microsoft Word full version (2019 Edition) is quite expensive with at least 109.90 Euro. German learner especially in Indonesia cannot afford it. Microsoft Word in German with Thesaurus in it is also not available in Indonesia. If we want to buy it, we should buy it online or direct in German countries such as Germany, Switzerland or Austria. It needs extra cost

There is on the one side an online open Thesaurus, but on the other side it contains not only academic words, but also other words for many specific purposes. Therefore, this study will develop a German Thesaurus vocabulary with the help of software that can be used by students to improve the skills of writing academic papers and especially thesis. By using the Thesaurus software, it is expected that students become easier to write their thesis so that the quality of German language is better. Students will also be more skilled in paraphrasing sentences in German, using expressions to write more varied citations at once to reduce plagiarism.

The student usually uses many similar words and familiar phrases in writing their paper by looking at the paper of other students. They always repeat in writing their paper using the same word as Machen (to do). Instead, student should use words, as for example durchführen (to do, suitable for an academic paper)) or Erstellen (to do, used typically in an academic paper). Based on the explanation above, a Thesaurus Software must be developed to observe if the competency of the students is increasing in writing their academic thesis.

The Thesaurus represents a list of some words arranged hierarchy, and which shows some relation among the words. According to Rochimah and Romy (2004: 125) there are many important elements in a Thesaurus like descriptor, non-descriptor or relation between term. The steps to set Thesaurus can be described below:

1. To begin with, we can install the software MIDOS Thesaurus. MIDOS is the abbreviation for Modular Information and Documentation System.

2. After the software MIDOS Thesaurus has been opened, the column is still grey.

3. Next, we can choose "File", "New" at the time of Thesaurus opened. All the Menu on Thesaurus will be active, and we can see all in the Window.

A list of academic words in German can be seen below in the table.

Table 1. Example of Thesaurus

\begin{tabular}{|c|l|}
\hline \multicolumn{1}{|c|}{ Word } & \multicolumn{1}{|c|}{ Example of Thesaurus (Synonyms) } \\
\hline & Durchschnitt (average) \\
& Querschnitt (cross-section) \\
& Mittelweg (middle way) \\
& Mittelmaß (mediocre) \\
& Überschlag (estimate) \\
Das Mittel (tool) & Medium (medium) \\
& Quelle (source) \\
& Hilfe (help) \\
& Maßnahme (action) \\
& Schritt (step) \\
& Methode (method) \\
\hline durchführen (to do) & absolvieren (to complete) \\
\hline
\end{tabular}




\begin{tabular}{|c|l|}
\hline & beenden (to finish) \\
& erledigen (to do) \\
& ablaufen (to expire) \\
& durchlaufen (to traverse) \\
& durchleiten (to transmit or to lead through) \\
\hline \multirow{3}{*}{ Die Fertigkeit } & Befähigung (qualification) \\
(ability) & Technik (technique) \\
& Talent (talent) \\
& Meisterhaftigkeit (mastery) \\
& Übung (exercise, practice) \\
\hline
\end{tabular}

Three of the words as examples above is an example of using Thesaurus. There are Synonym and some of certainly words, which are used in writing thesis of the German students in the German department at the State University of Medan.

\section{Review of Literature}

\subsection{The Concept of Thesaurus Software}

The Thesaurus is an alphabetical list of terms derived from archival classification schemes and arranged in a hierarchical way that demonstrates the relationship between terms. Thesaurus according to the English-Indonesian dictionary (Echols, 2003: 586) means a dictionary, encyclopaedia or other books that contain information. Meantime, the English dictionary (Longman, 2001: 1889) gives the meaning of thesaurus as a book that lists words in groups with other words that provide a common understanding.

The Big Indonesian Dictionary (Department of National Education, 2008: 1456) explains that the thesaurus is (1) a reference book in the form of a word list with its synonyms; (2) reference books in the form of information about various concepts or terms in various lives and knowledge. Kennedy and Schauder (2000: 145) explain the meaning of a thesaurus. It is a list of terms used and terms not used, as well as related terms (of using) arranged alphabetically.

From the description above it can be concluded that the Thesaurus is a list of words, terms, and synonyms systematically arranged according to the equivalent concept.

\subsection{The Stage of Making Thesaurus}

The steps to make a Thesaurus (Kunkel, 2019: 1) are as follows.

1. In the first place, we should properly install the software of Thesaurus MIDOS6 through the official website http://www.progris.de/m6info/index.htm. This software is developed in Berlin, Germany, and the demo version is free. We can use it for building, maintaining, managing und preparing any necessary information with the description of sentence structures. Information such as author, bibliographical data, patents, personal data, company information, product information or other data can be described by building of the Thesaurus software. We can efficiently generate the data in the MIDOS6 software automatically from any text format. The software can create autonomous retrieval applications for example for Windows and the internet, bibliographies and graphical statistics from the data of MIDOS too.

Usually, we get the data of the MIDOS in zip file. We can unzip it in any directory. It contains three files: setup.exe, demodaten.zip and m6.exe. The MIDOS6 of Thesaurus software is in the setup.exe. We can change the default path of the installation directory later. 
The software of Thesaurus MIDOS includes three editors for entering and changing information. They are database editor, table editor and hits editor and cause our work for building our own Thesaurus easier. The main website of the MIDOS6 Thesaurus has much important information for us, and we can learn how to build a thesaurus ourselves.

2. When we open the Thesaurus MIDOS software, the menus in the Thesaurus are still grey. We can alter the colour if we want to have other colour for our self-built software.

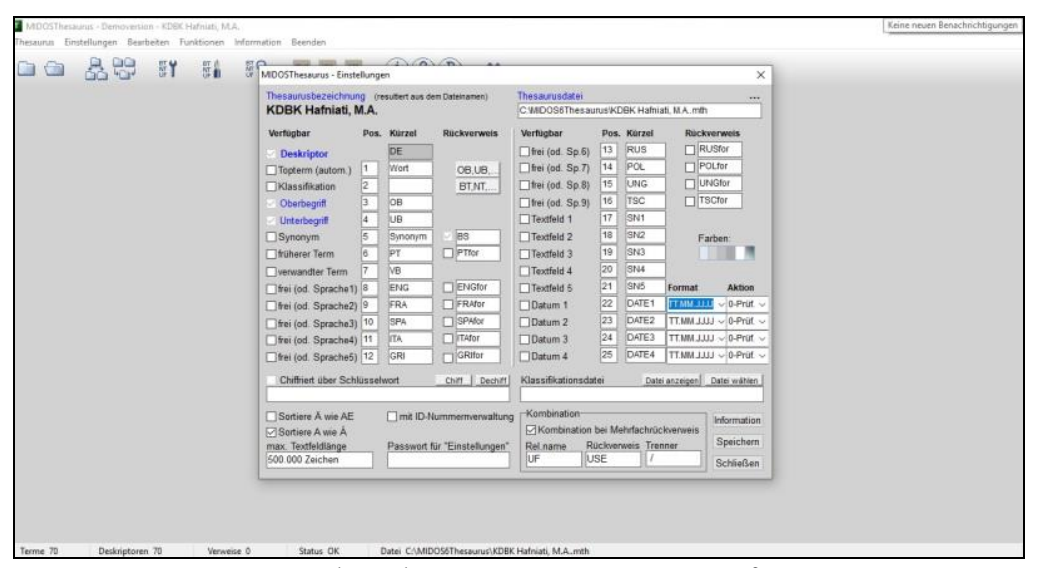

Figure 1. The Thesaurus MIDOS6 Software

3. At that point we can select File, New when the Thesaurus has been opened, all the menus, Thesaurus will be active, and we can see the parts on the window screen.

To do a search:

1. To write, press the back button, enter the name/word.

2. The name of word will instantly appear on the right-hand screen. This sophisticated software can sort automatically alphabetically.

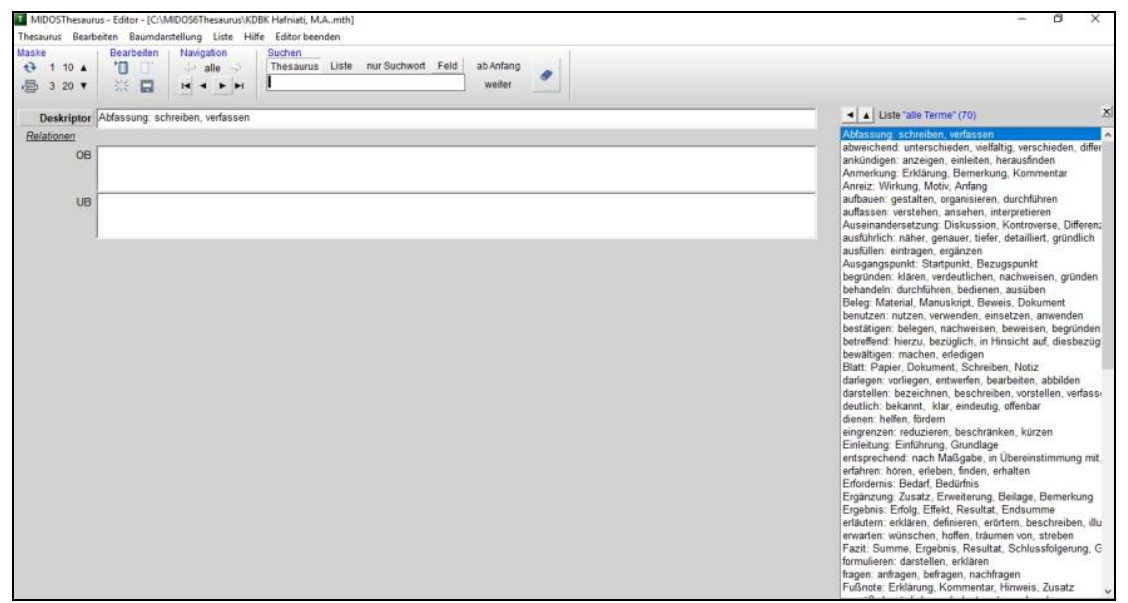

Figure 2. Searching in the Thesaurus MIDOS6 Software

3. We can import our data in the form of XML (Extensible Markup Language) or CSV (CommaSeparated Values). In a few seconds we get our data easily and can save them in our hard disk or in a USB memory stick.

4. When we complete our work with the Thesaurus MIDOS6 software, we can close the window of the Thesaurus. 


\subsection{The Concept in Thesis Writing}

Academic writing is a product of academic activities. Academic writing is writing that eagerly discusses a problem. The discussion was carried out based on the investigation, observation, data collection obtained through a study. Academic papers through this research use systematic academic methods to obtain academic answers to the problems studied. To clarify academic answers based on needed research, writing academic papers can only be done after a problem arises, which is then discussed through research and the conclusions of the research.

Academic writing as a means of communication in the form of academic knowledge uses systematic writing that can be accepted by the academic community through agreed systematic writing. In academic papers, academic features of work must be accounted empirically and objectively. Academic writing techniques have two aspects namely the writing style in making academic statements and notation techniques in mentioning the source of academic knowledge used in writing. Academic writing must use good and correct language. A sentence that cannot be identified which is the subject and predicate and what relationship between the subject and predicate is likely to be unclear information. The use of words must be achieved correctly. That means we must select the words by following the message what should be conveyed.

In research, writing material is used for academic papers in citing the statements of others or as a basis for the preparation of research. This academic statement is used for various purposes by following the form of the arguments submitted. The statement can be used as a definition in explaining a concept, or it can be used as a premise in concluding argumentation.

In the curriculum for writing a German Education Study Program thesis (2018: 1), it is stated that the thesis is an academic work of students compiled to encounter some of the requirements for successful completion of study in the undergraduate program (S1).

\section{Research Method}

The method used in this research is an instructional design from the ADDIE Model (Kurt, 2018). The ADDIE Model used for this study has five steps or phases: 1) the analysis phase, 2) design, 3) product development, 4) implementation and 5) validation.

\subsection{The Analysis Phase}

The creative process of asking these questions is often part of a needs analysis. During the needs analysis instructional, designers (IDs) will determine constraints and resources in order to fine tune their plan of action.

At this stage field observation is undertaken, to identify the information about the student's needs. Based on the need's analysis will be developed media/software that suits the purpose of learning.

\subsection{Design}

The design phase deals with learning objectives, assessment instruments, exercises, content, subject matter analysis, lesson planning, and media selection. The design phase should be systematic and specific. Systematic means a logical, efficient method that identifies, develops, and evaluates a set of planned strategies for attaining project goals. Specific means the team must execute each element of the instructional design plan with focused attention to detail. The design phase may involve writing a design document/design proposal or concept and structure note to aid final development. 
Planning stage starts with the selection of the vocabulary, word match, synonyms, Redemittel (phrases) such as Feststellen, Behaupten, Beschreiben, Definieren, etc., collection of valid materials and data sources, the creation of a glossary/terms, material development, location determination and tools used in developing Thesaurus software.

\subsection{Product Development}

In the development phase, instructional designers and developers create and assemble content assets described in the design phase. If e-learning is involved, programmers develop or integrate technologies. Designers create storyboards. Testers debug materials and procedures. The team reviews and revises the project according to constructive feedback. After completing the development of the course material, the designers should conduct an imperative pilot test; this can be carried out by involving key stakeholders and rehearsing the course material.

The development phase begins with the process of designing Thesaurus software with MIDOS6 Software. The program package MIDOS has many programs for the acquisition, maintenance and retrieval of data records for any unit of documentation. Usually, a file of MIDOS is a file that can be up to 2,1 Gigabyte in size. The characters in the MIDOS6 software can contain up to 500.000 characters for maximum 250 fields. It depends on the software, whether it is a trial version or a full version. For the research a trial version is used and each of the field has about 100 main words and their considered synonyms.

The Thesaurus software is based on a grouping of academic vocabulary such as synonyms, expressions in citation writing, as well as other academic words.

\subsection{Implementation}

The implementation phase develops procedures for training facilitators and learners. Training facilitators cover the course curriculum, learning outcomes, method of delivery, and testing procedures. Preparation for learners includes training them on new tools (software or hardware) and student registration. Implementation includes evaluation of the design.

After the media product learning software thesaurus validated, the product can be tested on the academic field to students of the German Program at the Universitas Negeri Medan in the subject Wissenschaftliches Schreiben (Academic Writing) during their practical lesson in the class. In this case it is necessary to give the students the software, to know if the Thesaurus software has some weakness or mistakes to be corrected in the future. At the beginning the students had a problem with the Thesaurus software, because it was new for them. Over time they enjoyed searching synonyms for German words.

\subsection{Evaluation}

The evaluation phase consists of two aspects: Formative and Summative. Formative evaluation is present in each stage of the ADDIE Model especially while the study has been conducted, while Summative evaluation is conducted on finished instructional programs or products.

The academic vocabulary thesaurus that has been developed will be validated by the learning media experts/computers. In this phase of validation, there will be advice and input from the media experts, so that the results can be developed better. 


\section{Discussion}

The Research "Development of Thesaurus software to increase The Quality of Thesis Writing Students in German Education" has achieved following, namely:

a. Thesaurus software academic vocabularies in German, which contains various academic vocabularies along with synonyms of such words. In this case, a Thesaurus with 400 academic German words has been developed. The words consist of 100 basic words that have three to four Synonyms including important Redemittel (phrases).

b. The book of Wissenschaftliches Schreiben.

c. Article journal on BIOLAE (Britain International of Linguistics, Arts and Education) on the website http://biarjournal.com/index.php/biolae/index.

\section{Conclusion}

Conclusions on this research regarding the development of a German language thesaurus for students are:

a. The Thesaurus software contains academic vocabularies especially synonyms of those words.

b. The Thesaurus software is composed of Redemittel (phrases) that are important in the writing of academic works.

c. The Thesaurus software provides many benefits for both students and lecturers. It can enrich the variation of vocabulary in thesis writing so that it can improve the quality of thesis writing.

d. The Thesaurus software is incredibly easy to use. The students or lecturers can make their own theme for words like academic words, German words, English German words, words for tourism or words for sport.

e. Trial Version of the Thesaurus software MIDOS6 is free and downloadable. However, it can contain merely up to 100 words. The full version can contain up to 1.000 .000 data records.

In the future it will be used in the learning process to know the effectiveness of Thesaurus in writing their thesis writing.

\section{References}

Departemen Pendidikan Nasional (Department of National Education). 2008. Kamus Besar Bahasa Indonesia. Jakarta: PT. Gramedia Pustaka Utama.

Echols, John M. 2003. Kamus Inggris-Indonesia. Jakarta: PT Gramedia Pustaka Utama.

Karmasin, M. 2011. Die Gestalltung wissenschaftlicher Arbeiten. Facultas WUV.

Kennedy, Jay; Schauder, Cherryl. 2000. Records Management: A Guide for Students a Practioners of

Records Management. Melbourne: Addison, Wesley, Longman.

Kurniadi, Fajar. 2017. Penulisan Karya Tulis Ilmiah Mahasiswa Dengan Media Aplikasi Pengolah kata.

Retrieved from: http://journal.unj.ac.id/unj/index.php/aksis/article/view/5306

Kurt, Serhat. 2018, December 16. ADDIE Model: Instructional Design. Retrieved from https://educationaltechnology.net/the-addie-model-instructional-design/

Longman. 2001. Dictionary of American English. United States: Pearson.

Ramlan, Ramlan; Farizawati; Hasrul, Saddam. 2020. The Effectiveness of Implementation of the MGMP Revitalization Program as a Media Increasing English Teacher Competency in Pidie District. Budapest International Research and Critics Institute (BIRCI-Journal): Humanities and Social Sciences. Volume 3, Number 1, February 2020. Page 95 - 103.

Retrieved from: http://www.bircu-journal.com/index.php/birci/article/view/665/pdf

Rochimah, S; Romy, Alexander L. 2004. Antara: Tesaurus Multibahasa Berbasis Komponen. Retrieved from: http://juti.if.its.ac.id/index.php/juti/article/view/265. 